\title{
La areté femenina en la sociedad homérica
}

\section{THE FEMALE ARETÉ IN THE HOMERIC SOCIETY}

Iván Giraldo Enciso

Universidad de Lima

igiraldo@ulima.edu.pe

\section{RESUMEN}

En el presente artículo se pretende elucidar el rol que cumplió la mujer dentro de la sociedad homérica. Para ello, se realizará una revisión del concepto de areté y su manifestación en esta sociedad. Luego, se abocará al análisis de la situación de la mujer dentro de esta comunidad y cómo se representaba la areté femenina. Por consiguiente, es necesario examinar las obras de Homero, tomando como ejemplo a dos de sus personajes femeninos más relevantes: Andrómaca, de la llíada, y Penélope, de la Odisea, destacando la areté de cada una de ellas.

PALABRAS CLAVE: areté, virtud, sociedad homérica, mujer, Homero, llíada, Odisea, Andrómaca, Penélope

\section{ABSTRACT}

This article aims to elucidate the role played by women within Homeric society by reviewing the concept of areté and its manifestation in Homeric society and analyzing the situation of women within this society and how female areté was represented. Therefore, it is necessary to analyze of Homer's works, taking as an example two of his most relevant female characters, Andromache in the lliad, and Penelope in the Odyssey, highlighting their areté.

KEYWORDS: areté, virtue, homeric society, woman, Homer, lliad, Odyssey, Andromache, Penelope 
On ne naît pas femme, on le devient.

Simone de Beauvoir

\section{INTRODUCCIÓN}

En el presente artículo analizaremos la sociedad homérica, el rol que cumple la mujer en ella y cuál es la relevancia de las virtudes que ella encarna, de su areté, dentro de esta sociedad paternalista, estamental y aristocrática.

Cuando se estudian las sociedades antiguas, se pueden encontrar lugares comunes. En cuanto a la división social, estas eran de orden estamental y con movilidad social casi nula. Y cuando se habla de la situación de la mujer dentro de estas sociedades, lo habitual es hallarlas bajo la tutela de algún varón.

Se ha dividido el presente trabajo en varios acápites. Se inicia con la definición

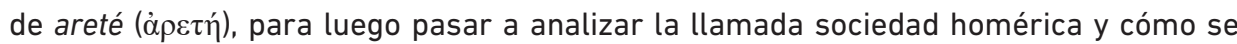
asumía la areté en ella. Dentro de esta comunidad se analizará el rol de la mujer; para ello se abordarán las dos obras cumbres de Homero: la llíada y la Odisea. Asimismo, se estudiará a dos personajes femeninos representativos en cada una de estas novelas:

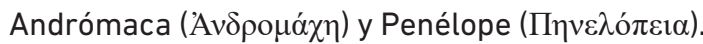

\section{ARETÉ (ẢPETH)}

Las grandes civilizaciones tuvieron una gran preocupación por el tipo de hombre que debían formar para poder mostrar todo su esplendor. Para este propósito es probable que se plantearan un ideal y formaran personas que lleven a cabo este propósito, quienes propondrían modelos educativos. Entre los occidentales destacan los helenos, quienes se esforzaron por desarrollar uno apropiado. Ellos buscaron plasmar este ideal de hombre a través de la paideia ( $\pi \alpha 1 \delta \varepsilon i ́ \alpha)$, que tiene diversas acepciones en nuestro idioma. Jaeger (2001) sostiene que esta palabra es difícil de definir, pues está involucrada en diversos ámbitos de la sociedad, cultura e historia griega. Podría involucrar civilización, cultura, tradición, literatura, formación o educación. Sin embargo, este autor sentencia: "Pero ninguna de ellas coincide realmente con lo que los griegos entendían por paideia" (p. 23).

De esta manera, se puede entender que una de las primeras civilizaciones en proponerse formar un hombre ideal fue la helénica. Ellos reflexionaron seria y conscientemente sobre la educación, paideia ( $\left.\pi \alpha \_\delta \varepsilon i ́ \alpha\right)$, y este propósito debería estar guiado por

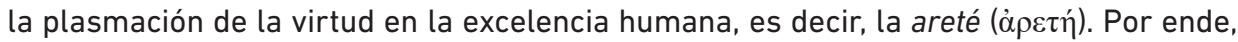
el valor más articulado y destacado que habría de ser alcanzado por los helenos era la areté. 
Al indagar sobre el significado de esta palabra llegamos a los tiempos homéricos, cuando se la definía como "ser lo mejor que puede ser" o "llegar a su máximo potencial humano". Es decir, una capacidad y potencia máxima que se utilizará para emprender alguna empresa; o la efectividad de un hombre y la habilidad que debía sustentarse en

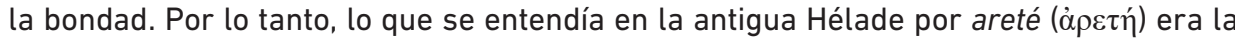
excelencia en general: quien la poseía alcanzaba esta categoría.

En los tiempos homéricos, esta palabra estaba íntimamente ligada a la posesión de las virtudes viriles, en particular el coraje y la competencia en la batalla. Este último sentido es conservado en las obras de Hesíodo y Homero.

La areté, siguiendo a Jaeger (2001), denotaba un carácter eminentemente aristo-

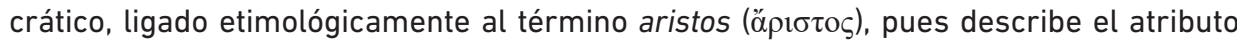
esencial y visible de la nobleza, que se hacía más evidente en el campo de batalla. Este carácter de clase aristocrático daba un estatus social privilegiado al individuo que lo poseía. Por esa razón, era hereditaria; pero no se trataba de una herencia automática, sino de una cualidad cuya existencia debía ser demostrada individualmente, sobre todo en el campo de batalla, y dependiendo de sus victorias o logros podía alcanzarse un grado más o menos alto.

Sumado a lo anterior, la areté, por su naturaleza aristocrática, incluía la sabiduría, que era hereditaria. Sin embargo, no se refería a la sabiduría racional, sino a la instintiva, la que otorgaba el don de una buena elección. En esa línea concuerda con Píndaro (1944), quien afirma: "Sabio es el que sabe por naturaleza" (p. 8). En consecuencia, aquel que hubiera adquirido sabiduría por aprendizaje obtendrá una areté inferior, pues, dado que esta es parte de su herencia y connatural a la aristocracia, no es posible obtenerla por medio de la enseñanza, y si se la obtiene, es de menor valía.

En la época homérica, la destreza y la fuerza sobresaliente fueron consideradas como atributos de la nobleza o la aristocracia, y ello llevó a las diferenciaciones sociales. El término

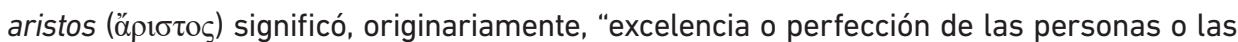
cosas". Este concepto y areté están íntimamente relacionados. Era natural para el hombre helénico de los tiempos homéricos, quien valoraba a sus semejantes por sus aptitudes, y consideraba al mundo en general desde el mismo punto de vista, el de los aristócratas.

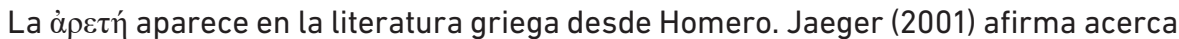
de este concepto lo siguiente:

Es usado con frecuencia por Homero, así como en los siglos posteriores, en su más amplio sentido, no solo para designar la excelencia humana, sino también la superioridad de seres no humanos, como la fuerza de los dioses o el valor y la rapidez de los caballos nobles. El hombre ordinario, en cambio, no lo tiene y si el esclavo procede acaso de una raza de alta estirpe, Zeus le quita la mitad de ella y no es ya el mismo que era. (p. 21) 
Con esto se remarca que la areté es un atributo propio de la nobleza. El mismo Jaeger (2001), al hablar de paideia, sostiene que el tema esencial de la historia de la educación helénica se basa en el concepto de areté, que está acuñado desde los tiempos homéricos. Agrega que el idioma actual no ofrece un equivalente exacto de la palabra. Podríamos decir, siguiendo al citado autor, que "la palabra virtud, en su acepción no atenuada por el uso puramente moral, como expresión del más alto ideal caballeresco, unido a una conducta cortesana y selecta y el heroísmo guerrero, expresaría acaso el sentido de la palabra griega" (p. 23).

Adicionalmente, durante la vida de Homero, su connotación tiene también carácter guerrero, unido al valor en el campo de batalla y la gloria militar. Y esto era connatural a la aristocracia militar, lo que vendría a significar una especie de don divino, que era connatural a su poseedor; era algo a priori que se obtenía en forma hereditaria; por ende, no se adquiría por dinero ni a través del aprendizaje o enseñanza.

El hombre que la poseía era aquel que era digno de admiración y honor; asimismo,

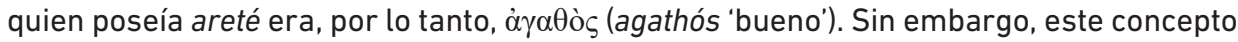
carecía de valor moral.

Por el lado del género, podemos decir que el papel de la mujer y su areté era un elemento esencial de sus costumbres. Al igual que el hombre, era juzgada según sus virtudes intelectuales y físicas; todo ello se medía también por la pureza de sus costumbres y la buena gestión económica de la casa (oĩ̄oc). Esto se relacionaba con la condición social y jurídica de las mujeres como amas de casa. Ellas eran las guardianas de toda buena costumbre y las primeras maestras de la tradición y la cultura. La belleza también era parte de la areté femenina.

La òjetí no está completamente terminada sino hasta la muerte del individuo, ya que es susceptible de cambios. Está vinculada a un individuo mortal con el que se le identifica. Lo sobrevive, sin embargo; se extiende en la memoria colectiva. Por ejemplo,

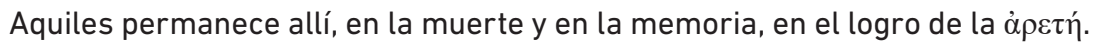

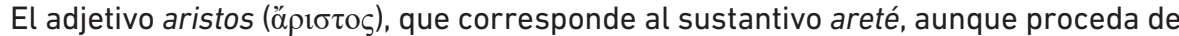
otra raíz, llevaba consigo la combinación de nobleza y bravura militar. Significa a veces noble, a veces valiente o hábil, pero no llega a tener el sentido posterior de "bueno", al igual que areté ( $\alpha \rho \varepsilon \tau \eta ̂)$, que no tenía la connotación de virtud moral. Esta significación antigua se mantiene aún en tiempos posteriores en expresiones formales tales como "murió como un héroe esforzado".

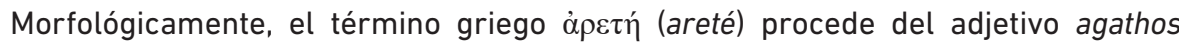
( $\alpha \gamma \alpha \theta$ òc 'bueno'), formando el comparativo. A su vez, procede de la partícula inseparable

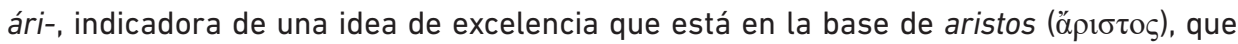
formaba el adjetivo superlativo de distinguido y selecto, y que en plural era utilizado para designar la nobleza o aristocracia. 


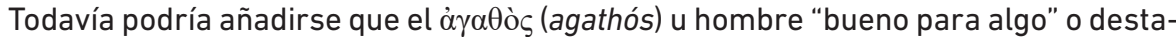
cado en algo - en especial para la excelencia o areté- tiene los medios de fortuna ya proporcionados o adquiridos por herencia. De ahí se deduce el hecho de que ella vaya unida a las grandes familias aristocráticas: esto involucra el prestigio social, poder político, los bienes que incluyen tierras y ganado. Estos se transmiten por herencia, ya que en los tiempos homéricos prácticamente no existían otros medios de enriquecimiento, puesto que no se comercializaba por medio de la moneda y el desarrollo comercial aún no era muy importante.

De esta manera, el noble o aristócrata, cuando no hace la guerra o gobierna a sus gentes, disfruta de esta riqueza con un refinamiento propio de su estatus social, de su linaje, de su nobleza. Como clase social privilegiada, la aristocracia muestra un gran refi-

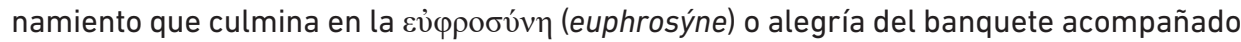
del canto del aedo.

Podríamos resaltar el sentido "ético" de ambas palabras. Derivan de una misma raíz griega que denota calidad y da ciertas normas de conducta, que no eran para el hombre común y corriente. La ética de la ciudad va a heredar su significado como una de las más altas virtudes, la exigencia del valor, que derivará en "hombría".

\section{LA SOCIEDAD HOMÉRICA}

Esta sociedad es una comunidad patriarcal y aristocrática, y a decir de Mireaux (1962), fuertemente tradicionalista. Estaba conformada por la clase social más antigua que se componía de propietarios de grandes extensiones de tierras. Pero no solo tenían la mayor parte del territorio, sino también el poder político.

Al estudiar esta época, llegamos a lo que se denomina la edad oscura de la historia de los helenos. Esta etapa corresponde a la época homérica, la cual no está exenta de interrogantes, al igual que el poeta y aedo helénico, de quien se ha llegado a negar su existencia.

Los entendidos en esta civilización ubican cronológicamente esta etapa entre el mundo micénico o prehelénico y el desarrollo de las polis. Este periodo se ubica entre los siglos XII y VIII a. C. Un referente sería Homero, que es la primera fuente y origen de la tradición literaria para los helenos y la cultura occidental. Este poeta es muy controversial, muchos dudan de su existencia y es considerado una figura legendaria. Hay preguntas que aún persisten a pesar de los veinticinco siglos de su posible nacimiento: ¿existió verdaderamente?, ¿cuál fue su oficio?, ¿fue ciego?, ¿es el autor de la llíada y la Odisea?, ¿vivió en el siglo vIII a. C.?

Podemos rescatar alguna información acerca de él. Sobre su nombre, según algunos, etimológicamente sería una variante jónica del eólico homaros, que significa "rehén, 
prenda o garantía". Para otros, el nombre proviene de un juego de palabras que significarían "el que no ve", que es una característica que se le atribuye al poeta: la ceguera. Sobre dónde nació, se mencionan las ciudades de Quíos, Colofón, Atenas, Argos, Rodas, Salamina, Pilos, Cumas, Ítaca y Esmirna.

Con respecto a la fecha de su nacimiento, se puede hallar un testimonio cercano a la época en que vivió. Heródoto de Halicarnaso informa que "Homero solo ha vivido 400 años antes que yo" (Historias, II, 53). Haciendo cálculos, estaríamos cerca del año 850 a. C., aproximadamente, pero no tenemos mayores fuentes acerca de este dato.

En cuanto a los que niegan su existencia, Colbeaux (2004) sostiene que la existencia de Homero surge de la necesidad de interpretar los poemas del citado poeta: “Cette invention d'une figure de poete répondait á un besoin pour qui tentait de lire et d'interpréter les poémes homériques"1 (p. 274).

Sin embargo, en la antigüedad helénica no hay duda de que el aedo es el autor de los famosos poemas. Aunque sobre estos poemas también se han abierto largos debates. Algunos filólogos afirman que no son de un solo autor, pues encuentran disparidad de tono y pausas que no concuerdan entre los poemas. A pesar de estas cuestiones, en general, la comunidad acepta a "Homero" como el autor de la llíada y la Odisea.

Los poemas homéricos nos dan un panorama de la época de oro de los helenos. En ellos se puede avizorar la organización política y social de la época homérica. Álvarez (2017) concuerda con Havelock en el uso pedagógico de los poemas homéricos en la antigüedad griega. La misma postura defiende Jaeger (2001): "Los poemas homéricos servían para enseñar los nómoi y los éthea a los griegos, es decir, las leyes consuetudinarias y las pautas de comportamiento personal. A este uso de los poemas Havelock lo denominó enciclopedia tribal" (p. 8).

Leiva (2018) hace un estudio en el que, a partir de los análisis de Adkins, describe la sociedad homérica y a los aristoi, quienes eran los que gobernaban por ese entonces, que

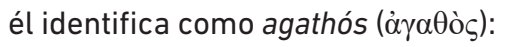

En la sociedad homérica, los hombres vivían en pequeñas comunidades relativamente autónomas denominadas oíkos. Cada oíkoi estaba bajo la comandancia de un jefe local referido, generalmente, como agathós. Es en el agathós donde se reúnen las virtudes morales que el grupo requería [...] porque reúne las características que el oíkos necesita. Estas virtudes [...] el coraje, la fuerza, la riqueza y la alta alcurnia, es decir, todo aquello que requiere un líder para defender su casa y sus súbditos. (p. 164)

1 "Esta invención de una figura del poeta respondía a una necesidad para quien intente leer e interpretar los poemas homéricos, pero constituía un círculo vicioso" [traducción del autor]. 
Vemos una sociedad aristocrática que ejercerá el poder desde su posición social privilegiada. Esta élite minoritaria, afincada con la aparición de las polis, evidenciará el renacimiento helénico a través del sistema de gobierno oligárquico.

Para ser parte de los aristoi se debe pertenecer a un genos ( $\gamma \varepsilon \dot{\varepsilon}$ os), que son pequeños grupos parentales conformados por familias patriarcales, de tipo endogámico. Y cada uno de estos grupos debía descender de un dios o héroe helénico, con lo que conseguen afirmar sus privilegios. De los genos surgirá el basileus (B $\alpha \sigma \imath \lambda \varepsilon v ́ \varsigma)$, el rey, cuyo poder no era absoluto, pues existían instituciones que lo controlaban y quienes las integraban también pertenecían a los aristoi. En esta sociedad homérica también se hallan los hombres libres, que eran comerciantes y pequeños terratenientes, entre otros. Ellos serán el sustento de los aristoi.

Para cerrar este breve panorama de la sociedad homérica, no olvidemos que los helenos convivían con sus dioses que, aunque inmortales, se parecían mucho a los humanos; por ello se sostiene que eran antropomorfos; además, tenían tantos vicios y defectos como cualquier mortal. Los dioses algunas veces demostraban pasión y otras eran justos, es decir, actuaban de acuerdo a su divina naturaleza. Por ejemplo, podían ser severos, y castigaban toda inequidad y ayudaban a los justos y piadosos; sin embargo, los olímpicos muchas veces fueron injustos, comportamiento atribuible a su antropomorfismo. Solo los aristócratas podrían obtener su areté, pues por su naturaleza y nobleza podían buscar igualarse a las divinidades. Por ello, un grupo de origen noble, los héroes, podrían lograrlo, pero en el campo de batalla o con la muerte, que los haría trascender al hombre griego común y entre sus pares.

Los hombres de la edad homérica viven, al menos por el pensamiento, en estrecha y constante intimidad con ese mundo divino o casi divino. Hollar una tierra, bañarse en un agua es entrar en contacto con uno de sus miembros. Cuando Ulises penetra en la desembocadura del riachuelo de la isla de los feacios, le pide que lo acoja. (Mireaux, 1962, p. 20)

\section{LA ARETÉ EN TIEMPOS HOMÉRICOS}

Cada sociedad construye o idea individuos sociales prototípicos a través de sus dioses, un dios o sus héroes. De estos personajes brotará una influencia positiva sobre el comportamiento moral de los demás individuos. Esta afirmación nos ayuda a sostener que este sistema se plasmará en el ideal heroico proyectado en el comportamiento de sus héroes o dioses, que los individuos de esa sociedad verán como paradigma.

Al estudiar estas características de la sociedad griega, podemos identificar en la conducta de la aristocracia un carácter competitivo o agonal (agón, ảyóv 'contienda, desafío, disputa'). Esto se evidencia por la búsqueda del reconocimiento por medio de 
méritos y éxito personal en el campo de batalla. Además, existían otros reconocimientos de tipo cooperativo, fundados en el respeto a instancias exteriores al individuo, o de tipo social. Por el equilibrio entre estos dos elementos, se determinó el tipo de sociedad y los fundamentos éticos valorativos de la antigua Grecia; este concepto será también parte de la areté.

En la época prehomérica y en la época en que el poeta vivió, es decir, la época arcaica, la nobleza constituía una sociedad exclusivista, elitista, que monopolizaba el poder, la justicia y la religión dirigiendo los cultos litúrgicos. Asimismo, estos nobles guerreros estaban siempre prestos a las confrontaciones políticas, que podían llegar hasta un enfrentamiento armado.

Es así como en la sociedad aristocrática se busca ser el primero, el mejor en la guerra y en todo ámbito, pues se desea el premio para lograr elevar la fama, evitando cualquier resquicio de deshonor. Por lo tanto, el éxito o fracaso es lo que condiciona la fama, la gloria u honor; lo contrario es el deshonor, por lo que no basta solo la intención ni el propósito. Lo que distingue a la areté son los resultados, que sin lugar a dudas deben ser positivos.

Como vemos, la areté o excelencia era en esos tiempos la virtud humana, aunque sin el contenido moral que hoy se le puede atribuir. Por lo tanto, el adjetivo que designaba al hombre excelente, agathós $\left(\dot{\alpha} \gamma \alpha \theta \dot{c} \varsigma^{2}\right)$, respondía al concepto de excelencia.

Espejo (1994) nos dice que uno de los valores supremos de estos héroes era el morir en combate, lo que era considerado como el honor supremo. Recordemos que nos movemos en un sistema de valores propios de una sociedad de guerreros. Además, por medio de esta gloria, el individuo logra un renombre, fama u honor dentro del medio calificado de los valientes. Por eso el reconocimiento objetivo del valor era la medida de la areté. De aquí viene ese deseo apasionado de gloria, fama u honor al ser proclamado el mejor, que es el impulso fundamental de la areté caballeresca: el héroe homérico no es realmente feliz si no se siente, si no se afirma como el primero, distinto y superior, dentro de su categoría.

Asimismo, como todo buen guerrero, su voluntad deberá estar dirigida hacia la aventura, y esta voluntad lo hará despreciar el peligro, pues está en la búsqueda de la superioridad en la acción. Todo esto denota el amor por sí mismo (philautía, pí $\lambda \alpha v \tau p i ́ \alpha$ ). A esto podemos añadir que los aristócratas de los tiempos homéricos buscaban la

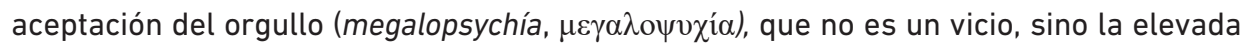
aspiración de quien ansía ser grande o ser honrado por su areté.

2 Agathós se puede traducir como "bueno"; sin embargo, no es lo adecuado para este tiempo. Para los tiempos homéricos sería "bueno para algo", en especial para la excelencia o areté. 
Además, ello involucra la lealtad para con el jefe y los compañeros de combate, a quienes no abandonaban, sino que auxiliaban valerosamente en el campo de batalla; de esta manera, la areté se torna imperativa; incluso llega a alcanzar el nivel de ley, pues tanto los mortales como los olímpicos deben actuar conforme a ella.

Siguiendo a Espejo (1994), afirmaremos que esta areté es agonística, ya que "convierte la rivalidad en un impulso poderoso configurador del comportamiento" (p. 130). 0 sea, este ideal heroico refleja los valores propios de una sociedad aristocrática guerrera, en la cual la habilidad física, el coraje y el liderazgo fueron los atributos más preciados en un ambiente de competición individual por el prestigio, dentro de un contexto rígido y proscrito de obligaciones.

El hombre homérico adquiere exclusivamente conciencia de su valor por el reconocimiento de la sociedad a la que pertenece; es así como el elogio (Ë́taıvos, epainos) y la

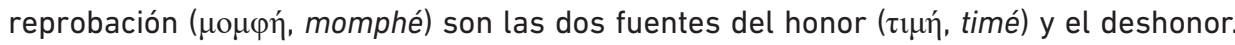
En consecuencia, esto denotará la cercana relación entre la areté y el honor, que en los tiempos homéricos no se podían desligar de la habilidad y el mérito.

Lo anterior nos muestra la disyuntiva homérica agathós-kakós. A este respecto, Espejo (1994) afirma que el carácter ético que desprenden estos términos se reduce, en este contexto, a la bravura física que demuestren los guerreros. Para ello menciona

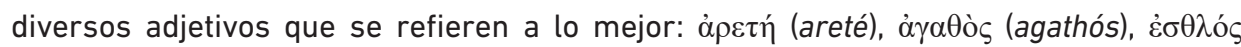
(esthlos 'valeroso, valiente'), $\chi \rho \eta \sigma \tau o ́ \varsigma$ (chrestos 'honrado, virtuoso'), $\beta \varepsilon \lambda \tau i ́ \omega v$ (beltion 'lo

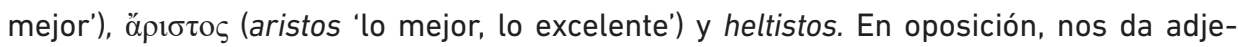
tivos que denotan lo peor o más denigrante, estos son kakotes, kakós, deilos, poneros, kakion, kakistos, aischron y elencheie. Respecto del primer campo, todos ellos designan en Homero las cualidades humanas más altamente estimadas; así, por ejemplo, agathós es el guerrero capacitado y valiente que en tiempos de guerra obtiene el éxito y en tiempos de paz goza de las ventajas sociales inherentes a su condición.

Espejo (1994) tiende a usar los términos moral o ética para referirse a lo que los griegos antiguos denominaban areté. Pero más adelante nos dice que si hay un elemento que define y articula estos valores, ese es la areté. Este concepto sería el compendio de todas las cualidades deseables en el hombre como excelencia interior y exterior; también podríamos definirla como aquello que hace del hombre un valiente, un héroe, o que es la expresión del más alto ideal caballeresco unido a una conducta cortesana selecta y al heroísmo guerrero, atributos propios de la nobleza.

Los dioses son portadores de una mayor areté y timé que los hombres. Si un héroe alcanza estas cualidades en grandes proporciones, puede cambiar de nivel y elevarse a la categoría de dios. Y esto es lo que realmente distingue a la mitología griega: la posición dominante que desempeñan los héroes dentro de ella, porque ellos iluminan con sus acciones y su naturaleza la posición y las limitaciones del hombre en el mundo. 
La finalidad de la areté es, fundamentalmente, el ajustarse a los juicios de valor universales; en otros términos, no hacer nada que no sea reconocido como kalón (hermoso). La dóxa (opinión) que los demás tengan de una persona o individuo representa su verdadero valor, su areté. Que uno sea honrado, alabado o no por los demás, es lo decisivo, marca su areté. Esta $\tau \mu$ (timé 'honor, estatus') está con frecuencia simbolizada en cosas materiales: de ahí que Agamenón no pueda quedarse sin una cautiva, que es su parte del botín, y Aquiles tampoco, hecho que generará la cólera de este.

Dentro de la $\tau \mu$ í hallaremos unos términos interesantes que tienen que ver con el

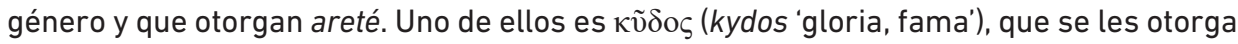
a los varones victoriosos que adquieren su prestigio a los ojos de los otros, a conciencia.

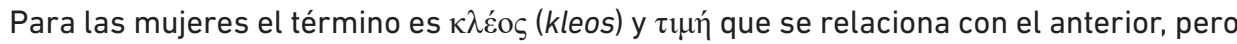
mientras este es relativo, es decir, va de acuerdo con el lugar que ocupa un hombre en relación con otro, kydos es una cualidad absoluta, como la fuerza.

\section{LA MUJER EN LA SOCIEDAD HOMÉRICA}

Las características de la sociedad homérica denotan que se basan en leyes consuetudinarias, encarnadas en la tradición y con un fuerte poder patriarcal. Se trataba de una sociedad cerrada y se basaba en la familia, donde el varón, cabeza de familia, la dominaba, por lo que la mujer aparecía en segundo plano. La mujer noble (que es hacia donde se enfoca nuestro estudio), a lo largo de su vida, se encontraba bajo la autoridad patriarcal de los hombres. En la cotidianeidad de su vida, pasaba de la autoridad del padre a la autoridad del marido o del hijo varón, ante la ausencia del marido o el padre. Asimismo, las que quedaban solteras, huérfanas o viudas sin hijos eran acogidas por algún varón de su familia paterna. Álvarez (2017) cita un pasaje de la Odisea donde Telémaco le habla a su madre, Penélope, y le aclara cuál es su lugar: el telar, la rueca y mantenerse en silencio. "La palabra debe ser cosa de los varones / todos, y especialmente mía. Pues mío es el poder en la casa" (llíada, I, vv. 358-359).

Ellas, las mujeres nobles, casadas, se dedicaban a la administración de la casa (oĩkos). Allí debían hacer cumplir las normas sociales y que se haga la voluntad del marido. Y aun esta actividad no la ejercían en forma autónoma, sino bajo la regencia del padre, esposo o hijo. Al respecto, Álvarez (2017) cita un pasaje de la llíada donde el héroe troyano Héctor le recuerda a su esposa, Andrómaca, sus tareas: "Yendo a casa, ocúpate de tus propias labores, / el telar y la rueca, y ordena a las criadas / que atiendan a su tarea; la guerra, en cambio, ha de preocupar a los varones" (llíada, VI, vv. 490-492).

Además, siguiendo a Álvarez (2017), las mujeres son definidas por su condición de "hija de", "esposa de" o "madre de" un varón ilustre (p. 9). Al ser consideradas como algo débil, debían estar bajo el resguardo y protección de los varones. Se observa cómo en 
ambos poemas se contrapone a la mujer a los valores guerreros, siendo vista como la imagen de la debilidad (p. 8). Las mujeres helénicas nobles tampoco eran consideradas ciudadanas; por lo tanto, no podían asistir al ágora y participar de las asambleas ni en los debates políticos, porque no tenían derecho a la palabra en público y, por lo tanto, no podían votar. Esto evidencia, además, que, al carecer de muchos derechos, ellas, a pesar de su noble cuna, no podían poseer propiedades ni enamorarse, por lo que el padre escogía el marido para sus hijas. La separación física entre hombres y mujeres era más pronunciada en las clases altas.

En el matrimonio ( $\gamma \alpha \dot{\mu} \mu \varsigma$ ) tampoco participaban; era una actividad en la que intervenían, exclusivamente, el padre y el futuro esposo. Este acto podía ser un intercambio comercial o una alianza estratégica del padre o de la familia. Puesto que el futuro esposo la ha "adquirido", él es su amo y señor; así pues, podía llegar a castigarla, devolverla a su padre o en algunos casos asesinarla si era adúltera. La diferencia de edades entre los contrayentes era notoria. El padre podía comprometer a su hija a los cinco años, pero celebraban la boda a los quince. Mientras que los varones optaban por el matrimonio alrededor de los cuarenta años.

La pareja no compartía las mismas habitaciones. El dormitorio nupcial ( $\theta \alpha \dot{\lambda} \alpha \mu \mathrm{\mu}$ ) lo

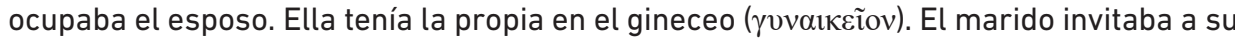
esposa o también podía hacer ingresar a otras mujeres, que podían ser sus concubinas o prostitutas.

Ella era la encargada de la continuidad de la familia; debía proveer de hijos al matrimonio, principalmente varones. Aunque había un gran número de fallecimientos durante el parto. Entre la nobleza, los recién nacidos estaban bajo el cuidado de las esclavas, pero con la cercana supervisión de la madre. Por ello, en su condición de esposa y madre, en ellas recaía el cuidado y educación temprana de los hijos. La concepción era una tarea propia de ellas, aunque disminuida, pues consideraban que el varón era quien daba el alma al concebido.

En la Hélade ellas hallaron en la religión una forma de escapar a esta realidad. Como sacerdotisas, se hacían cargo de la atención de muchos cultos públicos y el cuidado de los templos. En las procesiones religiosas asumían un rol principal.

Existieron festivales exclusivos para ellas, donde podían ser ellas mismas, sin la supervisión de algún varón. Entre estos festivales sobresalen las tesmoforias de Atenas (por Deméter y su hija Perséfone). En esta festividad no participaban los varones.

\section{LA ARETÉ FEMENINA EN LA ILÍADA}

Homero, en su poema épico la llíada, nos da un buen panorama de su sociedad, la Edad Heroica. Para los helenos era una sociedad con una atmósfera muy competitiva. 
Esta era una sociedad paternalista y agonal, pues tenía preocupaciones guerreras y heroicas. En ella los varones servían a la familia como guerreros, resaltando su areté en el campo de batalla. En cambio, las mujeres la habrían de reflejar en otro ámbito de la sociedad, el familiar, en la casa; es en el oíkos donde ella demuestra su areté externamente con su belleza, su fidelidad y perseverancia en mantener unido el hogar, con la eficiencia con que cumplía los deberes y tareas hogareñas que la tradición y los dioses le habían asignado. Ella debía dar a luz, sobre todo, a varones y criar a los futuros guerreros, quienes también han de elevar la areté de él y de su familia.

Según Guerrero (2000), el culto a la figura femenina pertenece a la cultura cortesana de las épocas caballerescas. A ella se le honra no solo como un ser útil para el hogar, sino, sobre todo y principalmente, como la que ha de guardar y mantener la tradición de una clase social orgullosa y cerrada como era la nobleza de ese tiempo, inculcándola a los hijos.

Así pues, en esta sociedad se considera a la mujer como una propiedad, posesión del padre o del esposo. Debemos resaltar que lo que da origen y forma a la llíada es la pelea de dos de los principales caudillos de la guerra de Troya: Agamenón y Aquiles, provocada por la posesión de una parte del botín de guerra: Briseida.

Homero nos presenta pocos personajes femeninos en sus poemas. De la llíada rescatamos a Andrómaca, quien representa y simboliza el amor, la fidelidad y el respeto de las decisiones de su esposo.

\section{ANDRÓMACA ('ANDPOMAXH): ARETÉ FEMENINA}

Llamada "la de los blancos brazos", era una hermosa mujer, hija de Ectión, rey de Tebas de Cilicia, quien fue asesinado junto a sus siete hijos por Aquiles, cuando este tomó su ciudad. Ella fue la esposa del héroe troyano Héctor, a quien suplicó para que no salga a enfrentar a Aquiles. A ella le preocupaba su esposo, pero también su futuro y el de su hijo, pues si el héroe moría, los dejaría en la orfandad y al ser botín de guerra serían esclavizados.

Homero nos presenta una escena dramática cuando el héroe troyano se despide de su bella esposa y su pequeño hijo. Ella, temerosa de que su marido caiga muerto por las armas de Aquiles, con lágrimas en los ojos y desesperada, le pide que no se enfrente a su rival e intenta aconsejarle, diciéndole:

— ¡Desgraciado! Tu valor te perderá. No te apiades del tierno infante ni de mí, infortunada, que pronto seré viuda; pues los aqueos te acometerán todos a una y acabarán contigo. (Ilíada, V, v. 407)

El héroe troyano, consciente de su estirpe y su areté, no la escucha y le recalca que la guerra y la política son asuntos de los varones, y las tareas que las mujeres tienen son otras. Héctor, conocido como "el del casco tremolante", busca consolarla sin dejar de 
recordarle sus deberes y obediencia al esposo. Con ello delimita las esferas de acción del hombre y de las mujeres en el mundo en que les ha tocado vivir. Así, el poeta muestra cómo ha de ser el rol de la mujer como esposa, núcleo de la familia, reproductora, dependiente y sumisa a su marido, y administradora de la casa.

Andrómaca está convencida de que ella y su hijo quedarán desvalidos ante la ausencia de su esposo. Por ello busca conmover y convencer a su esposo de no enfrentar a Aquiles:

Preferible sería que, al perderte, la tierra me tragara, porque si mueres no habrá consuelo para mí, sino pesares; que ya no tengo padre ni venerable madre [...] Héctor, ahora tú eres mi padre, mi venerable madre y mi hermano; tú, mi floreciente esposo. Pues, ea, sé compasivo, quédate en la torre - ino hagas a un niño huérfano y a una mujer viuda!- y pon el ejército junto al cabrahígo, que por allí la ciudad es accesible y el muro más fácil de escalar. (llíada, V, v. 407)

Pero no lo convence. Héctor se dirige al campo de batalla y Andrómaca se encierra en sus habitaciones. Ella está segura de la muerte de su esposo, pero él está seguro de que no debe faltar en el frente de batalla, cumplir con su destino y ensalzar su areté.

Luego, desde las murallas, observará el fatal desenlace. Sus ojos se llenarán de lágrimas y se preparará para asumir su destino, pues prometió una total fidelidad al esposo muerto y así lo hará.

Era un hecho cierto que después de la batalla el vencedor se apoderaba de las mujeres, los hijos, el oro, los mejores caballos y las riquezas del vencido, de allí los temores de Andrómaca. Pero la realidad le genera comentarios aún más negativos para el futuro de ella y su pequeño hijo. El último canto concluye con su amargo lamento ante la pira funeraria de su marido. Nuevamente se refiere a la suerte aciaga de su hijo y a la suya propia:

- ¡Esposo mío! Saliste de la vida cuando aún eras joven, y me dejas viuda en el palacio. El hijo que nosotros, jinfelices!, hemos engendrado, es todavía infante y no creo que llegue a la juventud, antes será la ciudad arruinada desde su cumbre. Porque has muerto tú, [...] Pronto se las llevarán en las cóncavas naves y a mí con ellas. Y tú, hijo mío, o me seguirás y tendrás que ocuparte en viles oficios, trabajando en provecho de un amo cruel; o algún aqueo te cogerá de la mano y te arrojará de lo alto de una torre, ¡muerte horrenda!, [...] ¡Oh, Héctor! Has causado a tus padres llanto y dolor indecibles, pero a mí me aguardan las penas más graves. $\mathrm{Ni}$ siquiera pudiste, antes de morir, tenderme los brazos desde el lecho ni hacerme saludables advertencias, que hubiera recordado siempre, de noche y de día, con lágrimas en los ojos. (llíada, XXIV, v. 725)

Su lado humano se hace evidente con toda su fuerza mediante las lágrimas que escapan de sus ojos; no son lágrimas de ira, sino de amor al ver que su esposo morirá en manos de los aqueos. 
La areté de Andrómaca en la llíada se manifiesta en su heroicidad y la fuerza de su femineidad como esposa, al respetar las palabras de su esposo; como amante que busca cuidarlo. Además, es la madre venerable y perfecta, por siempre, al expresar su preocupación por el futuro de su pequeño hijo, a pesar de su aciago destino fijado por los dioses. Por tanto, su areté y trascendencia nace y se fundamenta sólidamente en su noble actitud de amante y madre, tal vez menos grandiosa, pero más cercana y accesible al común de los mortales.

\section{LA ARETÉ FEMENINA EN LA ODISEA}

Como hemos visto, en los tiempos homéricos las mujeres eran apreciadas por la sociedad, pero dependían de la aprobación y permiso del varón, subordinándose a su padre, hermano o esposo e incluso a su hijo para poder participar en asuntos mundanos.

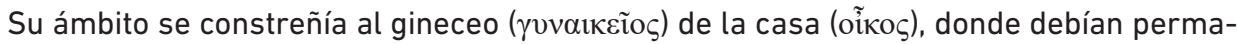
necer ocupadas en las labores domésticas propias de su situación. Algo que podemos ver en estas palabras dirigidas a Penélope por Telémaco, su hijo:

Mas tú vuelve a tus salas y atiende a tus propias labores, a la rueca, al telar y, asimismo, a tus siervas ordena que al trabajo se den; lo del arco compete a los hombres y entre todos a mí, pues tengo el poder en la casa. (Odisea, XXI, vv. 350-353)

En la Odisea el aedo heleno presenta a un conjunto de mujeres seductoras, algunas relacionadas con el mundo mítico (Circe, Calipso o las sirenas). Aguirre (1994) las considera "mujeres fatales", pues aparecen seductoras y hechizan a los varones con la belleza de su voz y cuerpo, provocando diversos desvaríos. Por ejemplo, Circe y Calipso son astutas, capaces de neutralizar y superar incluso las fuerzas del propio héroe de este poema: Ulises.

Además, nos presenta a un grupo de mujeres mortales. Entre las solteras, está Nausícaa, que representa la juventud e inocencia de la mujer. Es hermosa y núbil, que se deslumbra ante el mundo y el héroe ya maduro, Odiseo. $Y$ entre las casadas resaltan figuras contrapuestas: Penélope, mujer fiel, y Clitemnestra, mujer perversa. Ambas dedicadas al gobierno y tareas del hogar (oĩkos) mientras que los esposos se hallan ausentes, en el campo de batalla.

\section{PENÉLOPE (ПHNE $\Lambda$ OПEIA)}

Sus padres fueron el príncipe espartano Icario y su madre la náyade Peribea. Tuvo como características saltantes que era una reina paciente y esposa fiel, abocada a la administración del oíkos, entregada a su labor y siempre enamorada de su esposo. Estos rasgos encajan con los cánones de la mujer noble helénica, de allí que sus pretendientes 
no se atrevieran a faltarle el respeto ante la ausencia de Ulises, su esposo. Pero, como era costumbre, ante la ausencia del padre, es el hijo quien asume el rol tutelar. Su hijo Telémaco, al crecer, se sentirá llevado a disponer de Penélope. Ella, aceptando el rol de su hijo, se sentirá orgullosa y le obedecerá demostrando estar de acuerdo con su rol de mujer y, por lo tanto, de inferioridad con respecto a varón, al margen de su condición de madre. La actitud altanera de Telémaco ante su madre es una característica deseable de los helenos, porque es muestra de madurez y fuerza.

Penélope era una mujer menos exótica que Circe y Calipso; representaba a la mujer romántica, encarnando la devoción por la fidelidad y la prudencia, al esperar pacientemente a su esposo en su reino de Ítaca durante veinte largos años. Esto hará destacar y elevar su areté, lo que la sitúa como modelo entre los helenos al subordinarse ante los varones y manifestar su férrea fidelidad a su ausente marido, ante el asedio de sus pretendientes.

Es casi la única mujer de los héroes que participaron en el asedio troyano que se mantuvo fiel a su esposo y respetó su ausencia sin caer en brazos de otro hombre, demostrando la trascendencia de su areté. González (2006) refiere un mito acerca de Nauplio, quien fue a la guerra de Troya acompañado de su hijo Palamedes, quien murió por la traición de los aqueos. Se propuso vengar su muerte y convenció a las esposas de los héroes helénicos ausentes de serles infieles, tomando amantes. Clitemnestra, Medea y Egialea se dejaron llevar por los rumores del vengativo rey, excepto Penélope, quien, pese a haber escuchado el rumor de que su marido había sucumbido, se mantuvo fiel.

Ante la prolongada ausencia en Ítaca de Ulises, se presentaron numerosos pretendientes para desposar a Penélope. Ellos pretendían ser elegidos como su nuevo esposo. Mientras que ella les daba pretextos y no tomaba una decisión, ellos se hospedaron en el palacio y disfrutaron de la hospitalidad helénica, viviendo a expensas de la reina, dilapidando los bienes reales.

La reina fue muy ingeniosa para prolongar su decisión, pues no perdía la esperanza de la llegada de su heroico marido. Es famosa su idea de confeccionar una túnica para

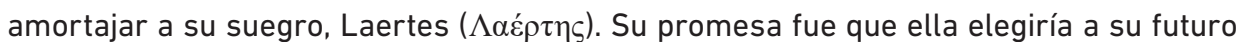
esposo cuando terminara de tejer la prenda. Para extender el tiempo, como parte de su ardid, lo que en el día tejía, por la noche lo destejía; esto lo pudo alargar durante tres años. Pero una de las criadas la traicionó y contó a sus pretendientes el proceder de la reina. Estos reaccionaron dándole un último plazo. Ante ello, Penélope propuso un torneo y quien resultara ganador sería el escogido para ser su nuevo marido. Había algo que solo podía hacer su ausente esposo, Ulises: tensaba su arco y lanzaba una flecha que traspasaba los aros de doce hachas. Ya en esos momentos su esposo había llegado, luego de su odisea, a su reino, Ítaca. Para evitar ser reconocido y castigar a los osados pretendientes, se disfrazó de mendigo. 
La intención de Homero en la Odisea es contraponer la figura de una heroína femenina, Penélope, al héroe masculino, Ulises u Odiseo. Por ello, dentro de su obra, Homero construye el personaje femenino de Penélope dentro del género épico, con una clara función modélica: resaltar fundamentalmente la fidelidad, dedicación, belleza, preocupación por los intereses del esposo y del oĩcoş. Todas estas son las características más saltantes que destacan y ponen de relieve su areté. Por eso su figura y fama será admirada por el común de los mortales, pues ha sido forjada por su carácter, su conducta intachable y sobre todo por su fidelidad, logrando el estatus de heroína y con ello un lugar entre los seres semidivinos.

\section{CONCLUSIONES}

Se ha podido evidenciar la preocupación de los helenos por el fundamento de su paideia, en la cual debían ser educados los niños y jóvenes, teniendo como uno de sus paradigmas a Homero y sus obras, la llíada y la Odisea.

Asimismo, el fin supremo de la educación griega, paideia $(\pi \alpha 1 \delta \varepsilon 1 \alpha)$, era formar al

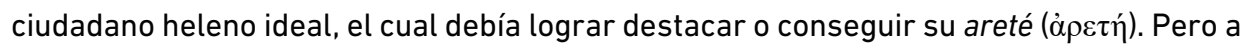
lo largo de la historia su significado ha cambiado remarcando algunos valores. Fue una columna fundamental para los helenos y desde ella, como si fuera el faro de Alejandría, resplandecerá y guiará a toda la cultura occidental.

Los dioses son un paradigma para el hombre helénico, pues ellos iluminan con sus acciones de valor y su naturaleza la posición y las limitaciones del hombre en el mundo. El héroe heleno proviene de la aristocracia y, por ende, su areté es connatural a su estatus. Él deberá elevarla con sus actos en el campo de batalla, pudiendo llegar al nivel de ser considerado en un semidiós.

La areté era inherente a la naturaleza aristocrática. Esta clase social buscaría demostrar su valía en el campo de batalla, en el gobierno de las personas o el cuidado de su ciudad a través de su ingenio e inteligencia. Este concepto, que se manifestó a través de Homero y sus obras, era inherente a los dioses y a dicha clase social.

En el análisis realizado a la sociedad homérica, se muestra que era una sociedad paternalista, estamental y aristocrática. Dentro de esta sociedad, el rol que cumple la mujer es de subordinación ante los varones. Sin embargo, a pesar de encontrarse relegada a un segundo plano, esto no implica que ellas no sean un referente en el ámbito social. Por ello su areté se refiere a su belleza, su obediencia al marido, su fidelidad y el cuidado que ellas prodiguen de las buenas costumbres de la familia. Lo hemos visto en la figura de Andrómaca y Penélope. 


\section{REFERENCIAS}

Aguirre, M. (1994). El tema de la mujer fatal en la Odisea. Cuadernos de Filología Clásica, 4, 301-317.

Álvarez, B. (2017). Papel e imagen social de las mujeres libres en los poemas homéricos desde la perspectiva de su alteridad. Parte I: las mujeres libres. Daimon. Revista Internacional de Filosofía, 70, 7-22. http://dx.doi.org/10.6018/daimon/198041

Arendt, H. (1993). La condición humana. Ediciones Paidós Ibérica.

Blundell, S. (1995). Women in Ancient Greece. Harvard University Press.

Calomarde, J. C. (s. f.). La mujer en la antigua Grecia. Género, vida y representación. https:// docer.com.ar/doc/nev5ece

Cantarella, E. (1987). Pandora's Daughters: The Role and Status of Women in Greek and Roman Antiquity. Johns Hopkins University Press.

Chaves, M. E. (2016). El anacronismo en la historia: ¿error o posibilidad? A propósito de las reflexiones sobre el tiempo en Carlo Ginzburg, Marc Bloch y Georges Didi-Huberman. Historia y Sociedad, 30, 45-73. https://dx.doi.org/10.15446/hys. n30.52609

Colbeaux, M. (2004). Raconter la vie d'Homére dans l'Antiquité. Université Charles de Gaulle.

Escolar, H. (1975). Historia social del libro. Grecia l: de Cnosos a Atenas. ANABA. https:// www.anabad.org/wp-content/uploads/2020/05/Historia-Social-del-LibroGrecia-I.pdf

Espejo, C. (1994). Religión e ideología en Homero. Studia Historica. Historia Antigua, 12, 9-20. https://dialnet.unirioja.es/servlet/articulo?codigo=106360

García-Peña, A. (2016). De la historia de las mujeres a la historia del género. Contribuciones desde Coatepec, 31. https://www.redalyc.org/jatsRepo/281/2815 0017004/28150017004.pdf

González, R. (2006). Penélope/Helena en el teatro español de posguerra. Revista Stichomythia, 4, 2-18. http://parnaseo.uv.es/Ars/ESTICOMITIA/Numero4/Sticho 4/ARTICULOS/Penelope.pdf

Guerrero, P. (2000). Andrómaca en la literatura griega: las versiones de Homero y Eurípides. Revista Signos, 33(47), 39-50. https://scielo.conicyt.cl/scielo. php?script=sci_arttext\&pid=S0718-09342000000100004

Heródoto de Halicarnaso. (2006). Los nueve libros de la historia (B. Pou, Trad.). eBooks Brasil. http://www.ebooksbrasil.org/adobeebook/nuevelibros.pdf 
Homero. (2002). Odisea. Gredos.

Homero. (2001). Ilíada (Introducción general, traducción y notas de E. Crespo Güemes). Gredos.

Jaeger, W. (1946). Paideia: The Ideals of Greek Culture (vol. 1). Oxford.

Jaeger, W. (1968). Paideia: los ideales de la cultura griega (2. ${ }^{\text {a }}$ ed.). Fondo de Cultura Económica.

Jaeger, W. (2001). Paideia: los ideales de la cultura griega (15. ${ }^{a}$ ed., vol. 1). Fondo de Cultura Económica.

Leiva, M. (2018). Ética y sociedad. A. W. H. Adkins y los valores morales en Homero. Byzantion Nea Hellás, 37, 161-174. https://dx.doi.org/10.4067/S0718-84712018000100161

Lerner, G. (1990). La creación del patriarcado. Crítica.

Madrid, M. (2014). La misoginia en la antigua Grecia. Ubi Sunt? Revista de Historia, 17(29), 52-59. https://www.academia.edu/31841865/La_misoginia_en_la_Antigua_Gre cia_El_odio_hacia_la_mujer_en_la_cuna_de_la_civilizaci\%C3\%B3n_occiden tal?auto=download

Mireaux, E. (1962). La vida cotidiana en los tiempos de Homero. Hachette.

Pérez, L. (s. f.). La mujer en la Antigüedad: su condición a través de la literatura. El Canto de la Musa. Revista Digital de Humanidades, 4, 21-58. http://www.elcantodelamusa.com/docs/2011/abril/doc3_mujer.pdf

Píndaro. (1944). Olímpicas II (M. Fernández-Galiano, Ed.). Instituto Antonio de Nebrija.

Piquer, R. (2008-2009). Penélope y el tejido del tiempo. XVI Seminario de Arqueología Clásica, Universidad Complutense de Madrid, España. https://webs.ucm.es/ centros/cont/descargas/documento12336.pdf

Ruiz, A. (2015). Historia de Grecia. Tema 5. Religión y modos de vida en la antigua Grecia. Universidad de Cantabria, Departamento de Ciencias Históricas. https://ocw. unican.es $/ \mathrm{mod} / \mathrm{book} /$ tool/print/index.php?id=882

Valdés, M. (2012). Exclusivismo político y religioso de los Eupátridas en Atenas arcaica. Dialogues d'Histoire Ancienne, 38(1), 9-36. http://www.persee.fr/doc/ dha_0755-7256_2012_num_38_1_3452 